\title{
如何合理而及時地改善北京市 目前建築工程的工作
}

\author{
A. B. 多洛普切夫

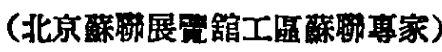

同志們要我做一湖報告, 談談從何着手來及 時而合理地改善北京市目前建築工程的工作。我 非常願意來做遥樣一橭報告。我之所以高興, 是

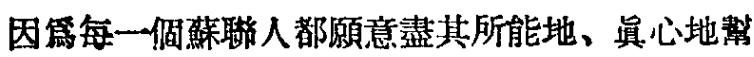
助偉大的中國人民建立繁策幸福的生活, 整助他 們迅速惯現祖國工業化這佪歷史性的任務。

當然, 很重要的一個問題就是不斷地改淮施 工設計和施工方法, 因篇要解决挒在我椚面前的 造樣一個完成五年計劃和資現國家工業化的任 務，在很大一方面就决定於在建築工程上能否做 到好、快、省。

莣房屋、工做、電站、娛樂場所等等, 需要 消耗大量的物資和人力。所以建策工程人員的治 要任務, 就應該是努力爭取以最好的方法來利用 通些財富。

但是要能够朝着改善工作的道路前進，就必 須要能够很清楚地看到自己的缺點。第了能更正 確地作出結論, 請允許我簡單地談一談一些主要 的點。

主要的、值得注意的缺點有下面幾個:

首先, 設計時處理得不經沾。

當然, 我還不能知道北京市所有設計部門的 技術情况，但是，我曾經有機會接觸到幾個建築 物的施工問題, 其中包括一蟑公共建築、一幢多 展住宅建策和一所很大的辦公大樓。根㹉這些房 屋的設計, 應當認篇設計工程師在處理平面佈㯰 的時候, 往往只用很小一塊面皘來處理建築屋的 主要部分, 而大部分面皘却塞滿了大量的、各種

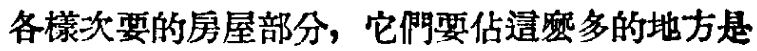

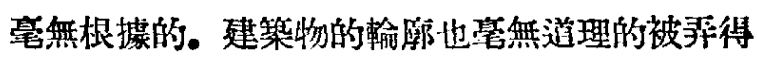
很複雓, 結果使施工組織和施工都很困難。結構 工程师在設計時常常是完全没有必要地把房子設 計成鋼解混凝土骨架, 踓然他們完全可以探用能

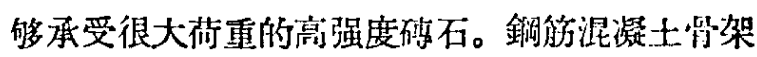
的柱子跨度很大, 結果就加重了漤仪的分量。混 㠜土都探用最谪的標號，踓然這亚没有必要。

所有這些都造成國是經济中所不可缺少的金 屬、水泡和人力的過分的消耗。

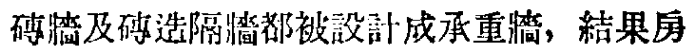

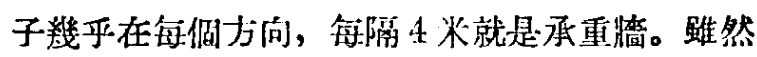

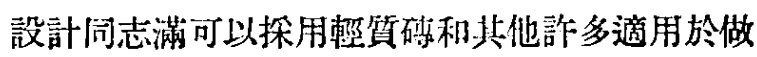
隔嘖的輕質材料。

所以, 要把改善建築工程問題和設計問題分 開是不可能的。

如果在設計房屋時能考虑到先進的施工方 法, 那麼施工人員立刻就能改進自己的工作。

毫無疑問, 用預製贴面板來代替建築物的外 部抹面裝修是具有詐多俊點的。但是, 假如設計 人員在設計時, 不設計成預整斯面的外部脽修, 而 設計成在脚手架上抹灰, 那䐴施工人員當然很難 來探用这種工厰化的方法了。假如建筑物的輪廊 都曲折不齊，那㦄施工人員就不可能使用起重設 備。我知道北京有一架結構很好的巨型起重機, 被從這個工地搬到另一储工地, 結果仍然不能利 用, 因䈔建築物的外形輪厥太被雜了。中國的工

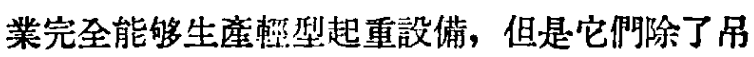

- 本交是作者在中國土木工程學會北京分會 1954 年會員大會上所作的報告. 
被不合理地消耗於做模板支柱的木材以外是果不 起品的什滤東西的。

假如設計圖規定所有的地板構造都需要用木

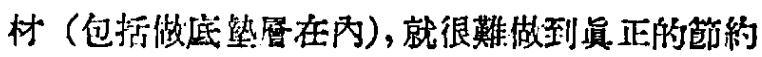
木材，蜼然在設部圖上我們磁到的全是鋼觔混凝 土掼恼。

這情, 我就放於做出第一個結論: 第了着手 徽底改密建策工程的現有情况，必須潇快地在設

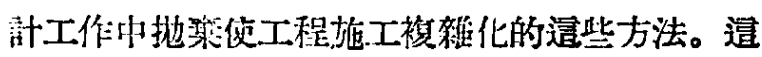
件工作目前正在設計部門進行, 但它推進的速度 是不解快的。施工人員有權要求更快地解决這些 設計上的問題。

在談下一個問題以前, 請謢我先談一個重要 的問題, 就是設計人員與施工人員在生產過程中 的閣係問題。

資本主義國家的管理方式多年來形成了如下 的這種關係：資本嫁無論想修建些什乷，首先都 不得不去找設計公司。設計公司在設計時, 總蛘

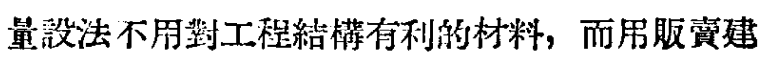
䑁材料游企業要他探局的材料, 這個問題結果也 多牛是在私人利忩的基礎上解决的。設計公司也 常常问资本家介紹一些施工工程公司。這種相互。 關伭就常使得賞施工能工程公司偶然不去猜测設 部人是的意圖, 没有探角設計人員所介紹的那個 公可活材料，面探时了别的材料的持候，工程公 闰就會受到排斥而有塄到破産的危險。這種資本 主義方式的鼠係, 就根深蒂固地促成了施工人員 肖目執行設計的情况。

㘏是過去和目前還通行在盗本主笔國家裹的 管理形式。

可是，當問題是關於在建築工程中人民財富 的消耗, 和如何更好地建设以順利地完成國家工 業化而不是篇了私人企業的持候，生產上的閣係 就應該有一，固根本的改變。

可以肯定地說，只有在設計人員與施工人員 共同友好合作下，打能做出好的設計桃。應装施 工人員有權来批評設計圖, 設計人員必須傾聽這

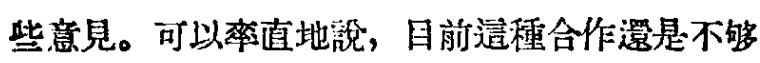
的, 目前設計人員遥是把自己看做是, 比方說, 悬主人，而施工人員，則是一個目目的執行者。

我涊篇，必須與䢧些資本主義的淺餘進行堅

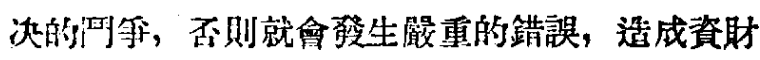

和時間的不必要的泿費。

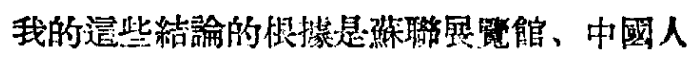
尼政治浫商會議大會堂及其它建贸設計的一些個 茄情况。

當設計人員脽離施工人員來做工作時，當科

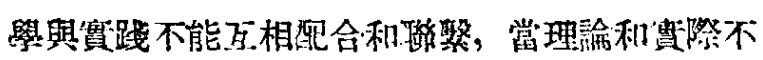
能五相配合和距系時, 任何問題要想很好很快地 解决都是不可能的。

現在来談談第二部分一一關於現有的一些施 工方法上的問題。在過去長期的生產顀践中巳經 相當快固地形成了造些施工方法, 塄些方法現在 正妨䅞着工人和許多工程技術人員發揮他們的創 造力。例如, 首先, 在施工侍總是在建築物的外 面架起十分筑重的外脚手架子; 其次, 只要有可 能, 施工人員立刻就架起榮重的內脚手架子。

應該承認，脚手架子是架子工人以繁人的本 領和勇政架起来的, 因鹄並没有人去考虑架設脚 手架子的技術保安問題。除此以外，也没有考㦄 到木材和營動力等的大量消耗。如果說，這些問 題都考虑到了的話，就會提出罾樣一個問題: 一 般說隶, 譄愫的脚手架子是否需要呢? 對此問題,

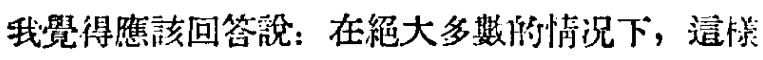
笨重的脚手架子在修建房屋時並不需要。毁際上，

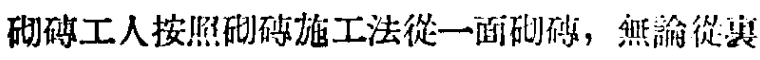

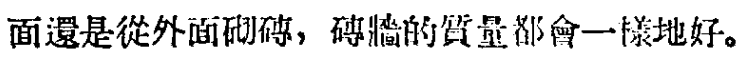
因此我深信，在任何情况下，上岸建峄都仃以探 用輕便的內脚手架子修建，其高度相党於一居楼，

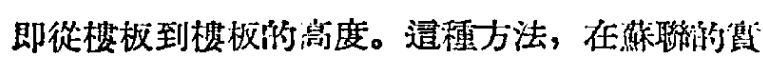
際工作中巳經完全肯定了, 而且既有敌省持間、 减低造㵋等很大的優點, 又不影響工程话星。

請注意這樣一個問題, 北京的詐多建筑物行

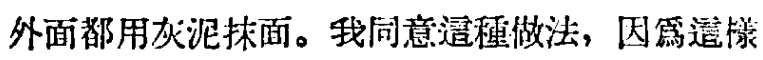

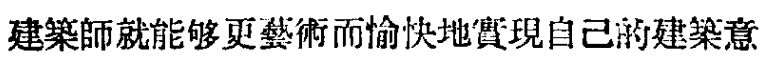
圖, 建築師總是力圖使建築物看承像是門石頭建 成的，把抹䤄割劃成憵多小地。

在脚手架子上抹面的方法, 普通称第“湿 林 面”, 也就是現場上最困難的一種沫面方法。造種 方法需要架設外脚手架子和很長的時間, 並且很

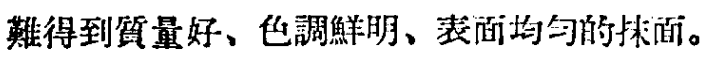

有必要在設計和施工中僯快地探倠成塊的預 
崒貼泊极來代替抹面。從以下的一些原因看來,

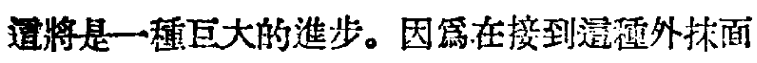
的設㖕圖以後, 施工人員就能够在修建房屋的同

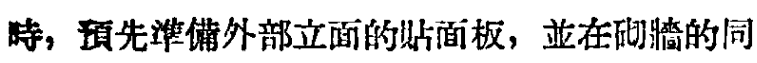

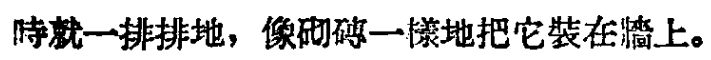

砌㽙可以濖愫進行: 把人造石或天然石勒脚 裝在基礎上，然後将預整贴面板劯在勒脚上，再

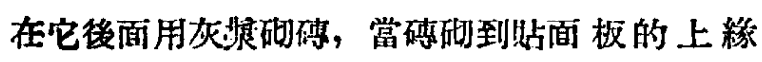
時, 就把鈎釷插入直徑不大於 6-8 毫米们小孔 队，造些小孔最好預先就做在贴面板上，用幾層 磷把鈎釷㻺上，然後再裝上一排貼面板。䍚是一 種可的支架方法, 可以保證結構的强度。

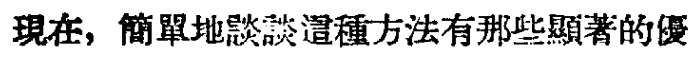
點:

1.不需要架設外脚手架子了，因篇没有䄐種 必要了

2.和完了破，建筑物的外面也完工了，

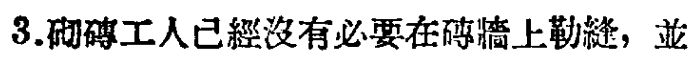
且由於碠砌體的車面比要進行抹面，砌碡工人的 工作也就大大地簡化了，勞動生產率也會顯著地 提高;

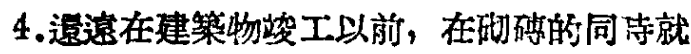
可以充分淮行室外工作（如修路、種㴻等等）。

5.所有逻一切，除了加快工作過程以外，對 抹灰工人和砌硙工人的技術的所需熟煉程度的選 摴也都容易了，因䈔遭種施工方法簡奛而容易做 到。

開於大地預䌘樓板，我不想多談，這程掼汉

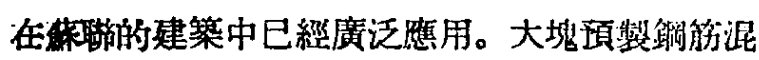
凝土樓板有 4-5 嘅重, 在住宅建築中是最好的結

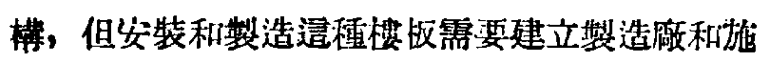
工的高度機悈化。這已經是工麻化施工的問題， 是另外一個題目了, 不是本題以內的問題。然而 在住宅建筑中門窗開口處, 倒是迫切需要探用預

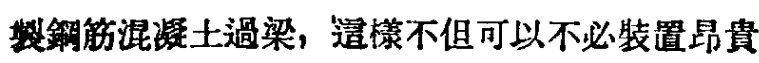
的模板，遭可以加速砌砵的過程。

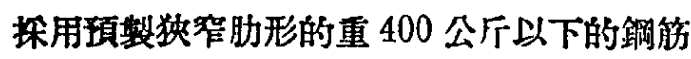
掍凝土掼板, 即樓板預製結檏, 是完全合理的。

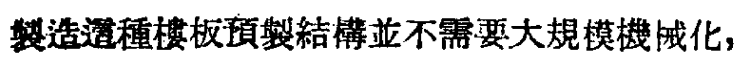
只要有輕型起重機就够了。這種暧型起重機中國 的工業很容易䌘造，霹此需要建立工地䌘造倣。

在北京軟木比硬木贵，並且應該業量節省木

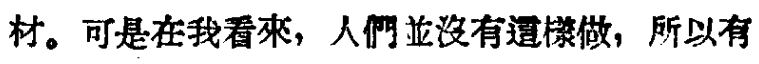

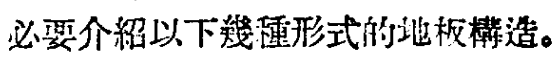

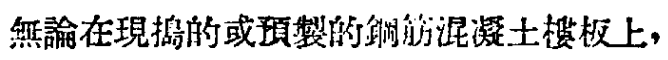

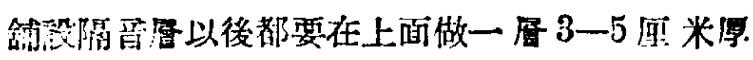
平整的水泥熱原。等水泥熟㕣完全硬化後, 約經 過 12-14 日, 最好是 20 日, 在上面学上加熱渦 的涯青二次, 但型青展的原度不得超過 4.5 滨米,

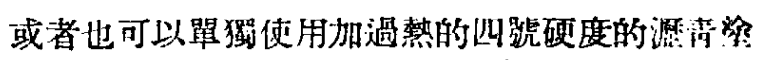

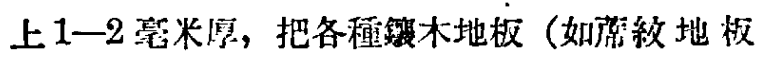
等）粘赑在上面, 這榜構造很簡單, 也很堅固。

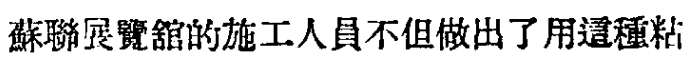
貼法做成的樣品, 並且决定大規模地, 把所有裂 木地板都按照造檑方法粘贴。

你們說，顀木地板造㵋很贵，根譃下列理由， 我可以回答說: 不對, 因焉:

1.計算一下有朴塾曆的長狹條地板和短狹佟

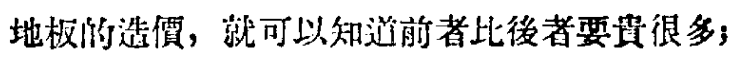

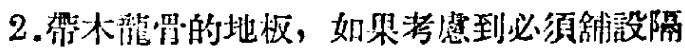
音屡和通風用空氣居, 那末在地板下的木龍骨就

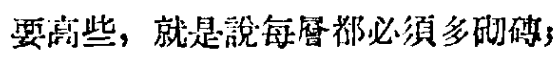

3. 最後, 也是最主要的, 就是能够得到不㒄 而酎久的結構, 而且技街操作最簡單, 並可以加 涑施工進度。

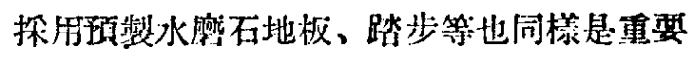
的問題。但是現在工程師們對待組䋨预製水麇石

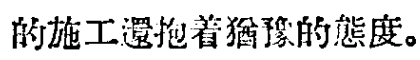

在斿工方法和結構方面，本來隹該更詳細談 秋, 但是由於時間限制, 我辞談下一湖問題了。

對於選一部分, 請允詐我做如下總結:

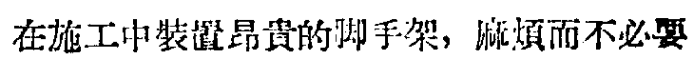

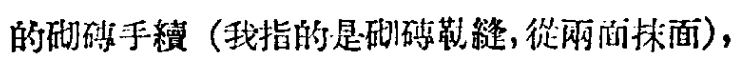

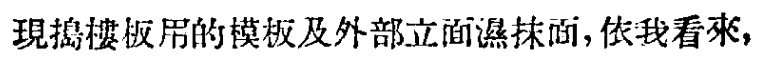

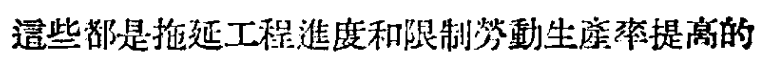
主要原因。

\section{三}

第三個問題就是工程資源利用得很不的多和不 完全的問題。

根䔲我經歷過的事賽, 我提出下夘幾點:

踓然㯰裏有很好的卯石，但我椚還是片砗石

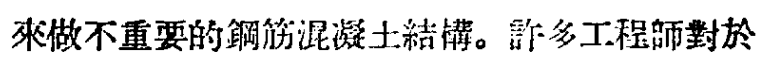

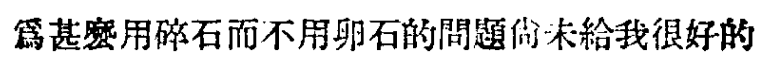


答盗，踓然的石要比明石贵得多。

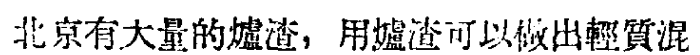

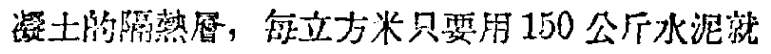
够了。如使用泡沫混㠜土隔熱居, 則每立方米要 沙清我 400 公厅水泥。

沟有人洘虑雨一種合理的模板, 這種模板容 多拆開，利用率高，也就是能使用多次。

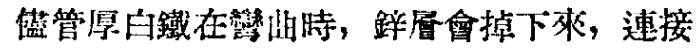

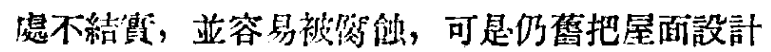
成很厚的白鐵。

竹子是一種很好㭙材料。它比木材輕得多,

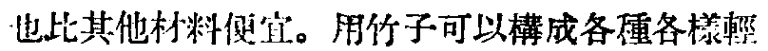

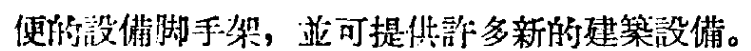

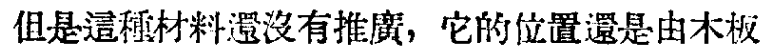
和激木所代桨着。用木板和圆术做的脚手架是非 常惧啲。

秥土及其所㹈成阿陶瓷材料，至今還只是用

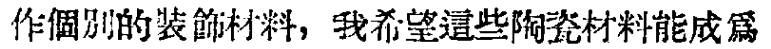
装飾房屋外面的主留贴面材料。

對於上述幾點及另外一些資源利用的問題， 在多次座談中都沒有得到全㓦的回答。

工程们們經常這樣回答: “我們没有經 壯於逻點我不完至同意。當然經驗是具有重大意

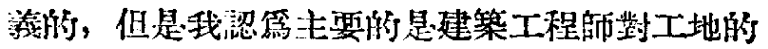

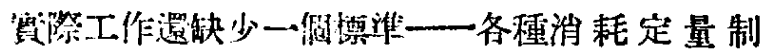
度, 特别是關於在工积成本上佔有很大比重的忉 料消耗定量制度。

我所以提出这件事, 是因第建築工程師在没 凅規定定額以前，浪費了詐多材料。遭些工程饰 在任何情况下都是慣於化賴传越脂资源條件的。

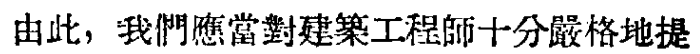
出下列幾點: 節約每一個釷子, 每一坮木頭, 盡

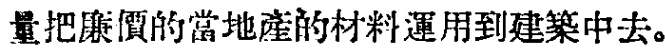

倠工人員和設計人員對使用人民的量電物質 村料是焦有重大的责任的。

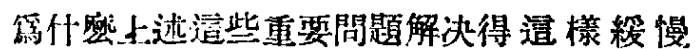
呢? 管信如如何加速解决造些問題呢?

要加速解决遗些問題, 首先要在建策公司設

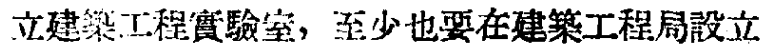
一倜能频室。

現杜我們問問自己，是否我钥一工程師

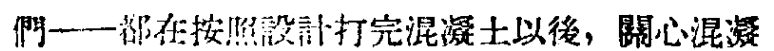

土最後的强度呢? 如果老貨、坦白地回答, 那昤 絕對可以說, 除了少數例外, 我們是不鬥心逜倜 問題的。

望際情况是造漛的：我阴在按照設計推行工 作時, 以及在選擇混凝土時没有充分地检查。本 來要的是 110 號强度的混凝土, 實際上却是170180 號; 本來要的是 140 號强度的混凝土, 筫際上 却是 200 躆的强度。總之没有筫驗室的試驗和分 析，我椚就會浪費大量的水泥。

事先不經過實驗空研究和試驗, 是很難推廣 新材料、當地産的材料以及各種裝置和設俑的新 構浩的。

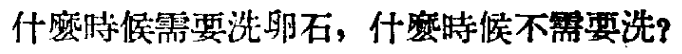

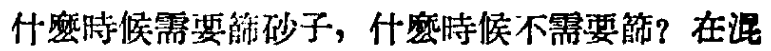
凝土工程中, 利量砂子和石子是否常常要潐確㺫

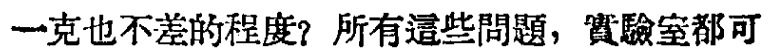
以很容易地回答出來。

但因篇没有貄築方面的䁈驗室, 施工人員就 無論在什麼情况下都要筑砂子, 洗石子, 秛量每塊 小石塊, 賽際上譄些工作根本不需要經常做的。

賞然, 我這哀只引用了一些调別的事䆩, 但 是, 如果把造個問題更深刻地研究一下, 那末你 們就可以得到這樣一個結論：翼驗室是解决重要 建築任務的首要的助手。

\section{四}

現在請譲我談下一個問題。

在現場進行勞動力使用情况的分析是非常必 要的。率植地說: 目前現場對勞動力的使用是浪

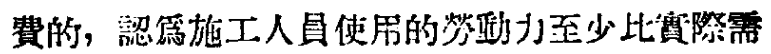
要的多一倍多, 大概也不算說政。假如不僅把工 資, 而且把宿舍、運輸費用等都包括在內, 沮對 國家就是一筆很大的開徐。

北京某一大工地曾計算了計時工㗄時一個研 硨工人一天毁際平均能砌的嘈數和一個架子工人 禁脚手架及木工支模的本比的一天工作量, 然後 把定額提高一倍牛，再將這些組的工人改第計作 工資。結果, 定額似乎是定低了, 因篇各組都超 額完成了定額，有些組甚至超額到 170-200\%。

從邆些經驗可以得们一個怎樣有根㨜而又正

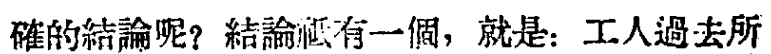

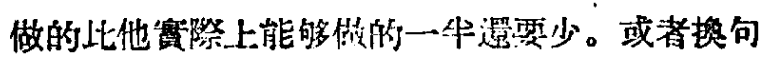


活話，他何一牛時間是在工作，另一牛時間則在： 休息或者是虑於看不到的窝工狀態。虺就是說， 国家給工人的錢有一半並不是勞㔚的報酬，而是

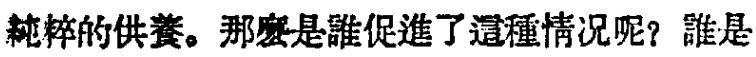
使工人們得到塄些鐇的中間人呢? 不管選件事情

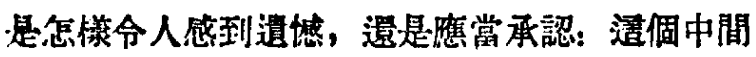
人就是工程師和领導幹部。

如果從這方面来看㯰個問題，那末站一定可 以得出下面這個絬論: 必須盡可能快地規定工人 帣動的定額，㩇可能快地在建築工人中推行計件: 工資制。逿是一個很重要的問題。在各工種建筑 工人全部訂立梳一定額以前, 一定要求先在某些

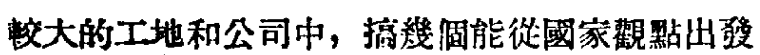
算决狺些問題的小組，而篇下面這些原則打下基 喽: 力求達到, 如果工人一天能正常工作八小 㭙, 就可以得到其應得的全部工資。另一方面, 办不允許工人不按照融會主義的要求來很好地工 作，而取得不是用勞動得来的工資。而如果工人 表現很大的勞動熱情, 超額完成了定額, 那末他 就有權得到較訃特工資更多的工資。

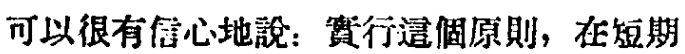

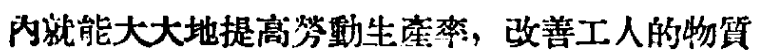
生活，也就是提高工人的工资。迡個原則將篇國 家故省許多資金。這個原則將會加快工程的淮展， 而只用較少的工人。最後, 這個原則能鼓践工人 努力提高自己的熟梾程度。如果施工人員都能深

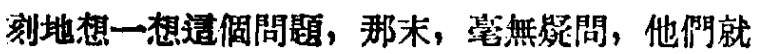
特得出結論: 㙅改進建築工程水說, 皘些都是和 空氣一槏的不可缺少的東西。

\section{五}

我現在很簡短地談一談工人的工資怎樣收編 㹁件工資的問題。

1. 必須惻定工人工作的㭙間，佂這個基礎上 行政與工合、工人代表進行坫商，制定臨時定額。

2. 造些臨時定類必須經過重新審言丁和调整。

3. 根捦許多工地制定的邆些定額, 經過网年 右右的時間，可以制定一個統一的定額。制定遏 槏的定積對於所有的建築部門都是必須的。这個 定額經過較長時間後還需要重新審訂，因第施工 組織的方法是不断地在改進, 然動生產率也在不

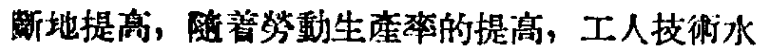

平世會不斷地㘧最。

$$
\text { 乐 }
$$

下一满重要的問題，就是對推行建勧工程的 （即使是某些部分的）工廠化的重要性估部 不 足 的問題。

褧我們來研究一下，建築工程的工廠化究誢

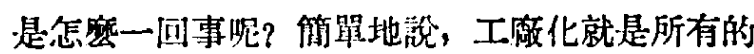
建築部件由各種配件製成; 或者不是由配件䌘配 成，而是將部件做成能直接安裝的形式。它們不

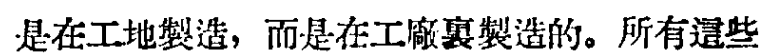

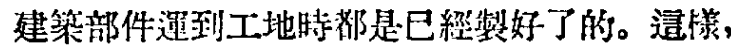
在工地上所進行的就不是建築房屋, 而事听上就

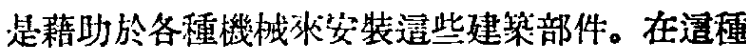

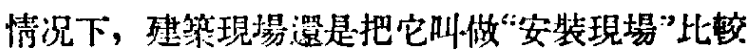
姃確些。

我世知道，篇了完成逼個任移，就必須建立 建築工廠化的工業，也就是要蓋起大量的生産建

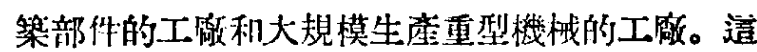
需要一定的峙間, 是將来的事情, 而且將夾也必 定要做的。但是現在就應當替慣於探用工故化的

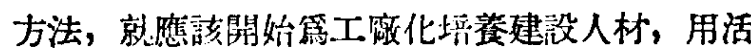

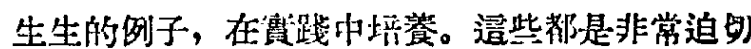
和非常重要的事情。

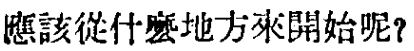

第一, 就是從設計開始。

就算只篇北京枋着想，設計機構也應該共同

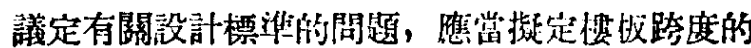
標注，梁的標淮和行洞、莜洞的標淮等等; 至少 也應當制定出澄些構件的標隻圖紙。遭是不難做

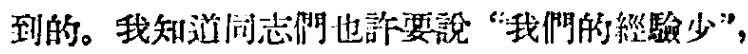
但是根據下列原因，可以說㩊是不正確的。設計 機構是可以找人桃其问商量的，闰時也可以利用 現有的資料，這些資料他們有很多。間題只在 於：必須將造個問題賞作是首要的問題，而且應 該將它做好。

另一方面，施工人貪不雔該只坐着等街設計 人員在設計上解决裝配問題和部多建築部件的標 售問題。現在施工人員也已縒有可能來探用工薮 化的構件。這我可以舉出一些例子。

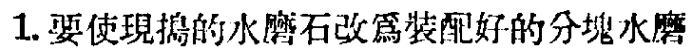
石, 也就是改成裝配式的水缕石地板一一這亚不 
需要没訃機構的設訫。

2. 啝禁餇解㭙是桨禁好的安上去, 而不是一 桂根地安上去一道也不姴設計的。

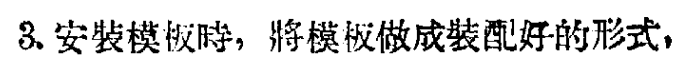
世呵以不用桎計。

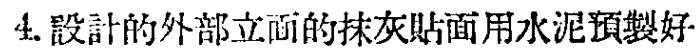
的少酒板来做，也不朋設計。

5. 最後, 斿工人員應當齿影響設計人員, 以 促進他們能在設計中探伤签侹的裝配好的樓板; 不能接受那種没有洘箩到目前可能探用而且很方 健的工廠化構件的設計。

我想基可能地解釋一下，探用工廠化栍工並 不是第探胕而探用, 而首先是第了加速施工的速 度和减低建築的成本。請想一想，我們没有工廠 化的方法, 會得到什森結果。模权的成本大大地

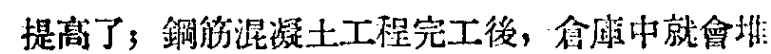
满大量不能使简的損壞了的木材。這樣, 就白白 地浪費了㨽多財富。假如施工機構有一個固定的、

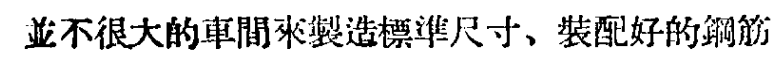
混凝土構件，那末就可以有把握地說：木材的游 耗量以工程的邆一部分来說至少就能隇少 $9 / 10$ 到 14/15。要是施工機構有一定固定的模㤆車間, 那 末就很容易探用不是只能利用一[䜣，而是能利用

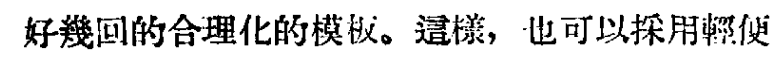
的標淮型式的脚手架和其他各種来陌。

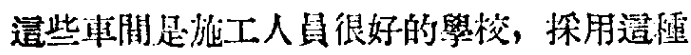
方法, 施工人員能更快地扰亲舊的、策重的而且 北費很大的施工方法。阔時，在施工上利用裝配 好的構件和部件，能促使施工過程機械化。

最後，问以做一個總綃：施工部阴應該立刻 開始建立（即使是不很大的，但是固定的）生产

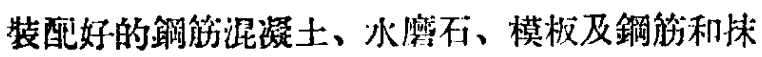
得的蛇宿板等等的車間。

订能有人會向我提出一個問題, 修建這些工 㣘的踐從那兒来呢?

济相信我，或者請你們算一算，那未你們就 曾相停, 篇了進行工程而建案的臨時建築物, 以 及由於沟有建立固定的車間而椇壤的材料, 塄些

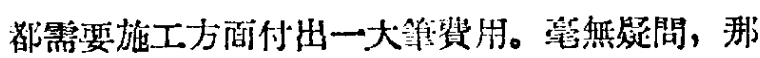
律費居是比建立車間更大，况且迲些車間對於我

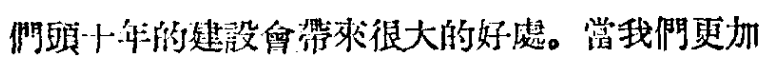
“富裕一些的㭙候, 我們就可以新建許多大工府桼
代替這些車間, 狺已經是第二階段一一建築工程 大規模工激化的階段。

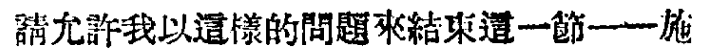

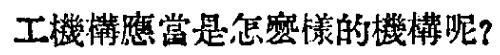

在目前施工機構基本上還只是工人和领煘人 員所組成的工作榢, 工地完工以後除了大量的剩 餘輔助材料和拆除了的䠦時趡桇物以外, 美不多 什㤎都没有了。施工機構在建築一所房屋以後就 礁該建立起一個某種車間, 建貿完另一所房屋以 後就建立起另一個車間。造樣, 施工機構就逐年. 地有了自己的基地一一自己的建築工程工廠化的

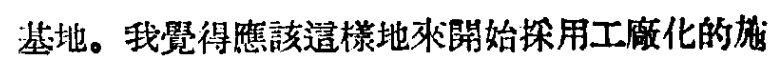
工方法.

\section{七}

、因絾時間不够，已經不可能談到其他對於施 工迫切需要解决的一些重要問題. 我所指的是機 械化施工的問題和管工季節性的問題, 即冬季施 工的問題, 逜些都是迫切地需要及時解决的問題。 不過我是有意這㥆做的，因篇我涊篇运些都是独 立的問題。

我請求北京土朴工秷學會, 這些報告代要由

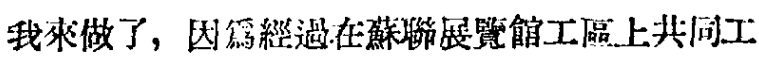

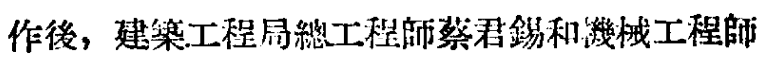

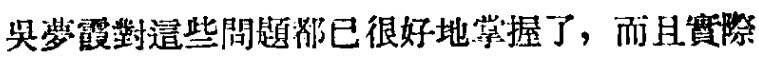
上已經大規模地在工作中應用了，问時已有了很 好的絬果。所以最好是請他們做堷些問題的報告。

我現在談談最後一個問題, 就是交流經驗的 問題。必須立刻成立一個䋑常性的北京建築工程 人員工作成就的展覧會。無諭是新的建築材料、 学動組織的新方法、新型結構、機械化方面的一 切, 不諭怎麼小的成就都應該展覽出來, 所有逭 些東酩都隹詳細地介紹給工程師、技衔員及先進 工人椚。不大咅化地推廣新東西, 没有廣泛的交 流經驗，是很䧼推廣新的和更好的能工方法的。

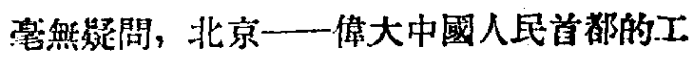
程師和建案工人們都會了解這一點, 同樣, 施工

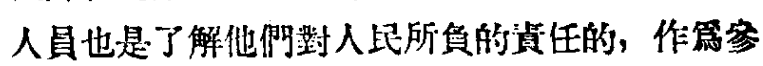
加建設首都的建築工程人員，他們㮣該是中菜人 地共和或古國各城市的建築工程人員的榜榡。

[司徒香生燡] 